\title{
Os Gestos Recorrentes e a Multimodalidade em Aulas de Química Orgânica no Ensino Superior
}

\section{Catchments and multimodality in organic chemistry teaching in college}

\author{
Renata Reis Pereira, Eduardo Fleury Mortimer e Luciana Moro
}

\begin{abstract}
Resumo: Professores de ciências da natureza normalmente utilizam vários modos de comunicação durante a construção de significados em sala de aula. Nesse sentido, o estudo da multimodalidade tem um importante papel nas pesquisas em educação em ciências. Neste trabalho, analisamos o uso dos gestos recorrentes em conjunto com outros modos semióticos durante o compartilhamento de significados em aulas de química orgânica do ensino superior. A análise foi realizada a partir dos vídeos das aulas gravadas durante um semestre. Procurou-se responder às seguintes questões de pesquisa: Como ocorre a recorrência dos gestos e em que conteúdos os gestos recorrentes predominam? Como os diferentes modos se articulam na construção de significados relevantes para a química orgânica? A partir da identificação dos gestos recorrentes e de suas relações com os conteúdos trabalhados, conseguimos identificar conceitos que são considerados essenciais no entendimento do conteúdo de química orgânica. O professor constrói significado por meio da interação entre esses modos semióticos. Compreender o papel desempenhado pelos vários modos permite a este fazer escolhas dos modos que julga mais apropriados para serem utilizados no ensino de um determinado conteúdo.
\end{abstract}

Palavras-chave: ensino superior, química orgânica, gestos recorrentes, multimodalidade

\begin{abstract}
Natural Science professors usually use several modes of communication to make meaning in classroom. Thus, the study of multimodality makes a worthwhile contribution in science education researches. In the present article we evaluate the use of catchments in conjunction with other semiotic modes by an organic chemistry professor. Classes from a whole term were video-recorded and analyzed. We noticed that the professor conveys meaning through the interaction of different semiotic modes. We sought to answer the following research questions: How catchments occurs and in which contents they predominate? How different modes are articulated in the construction of meanings relevant to organic chemistry? From the identification of catchments and their relationships with the content, we identify concepts that are considered essential in understanding the content of Organic Chemistry. Understand the role played by different modes allows the professor to make choices in the ways that are more appropriate for teaching a particular content.
\end{abstract}

Keywords: university teaching; organic chemistry; catchments; multimodality

\footnotetext{
Renata Reis Pereira (reninharp@ hotmail.com), licenciada em Química pela UFMG, mestre em Educação pela Faculdade de Educação da UFMG. Belo Horizonte, MG - BR. Eduardo Fleury Mortimer (mortimer@ufmg.br), doutor em Educação pela USP, pós-doutorado na Washington University of St. Louis, USA, e Université Lyon II, França, é professor titular da Faculdade de Educação da UFMG. Belo Horizonte, MG - BR. Luciana Moro (moro@icb.ufmg.br), doutora em Patologia pela UFMG, pós-doutorado em Educação pela Faculdade de Educação da UFMG, pós-doutorado na École Supérieure Normale de Lyon, França, é professora associada do Departamento de Patologia Geral - ICB - UFMG. Belo Horizonte, MG - BR.
}

Recebido em 14/10/2014, aceito em 28/11/2014

A seção "Cadernos de Pesquisa" (exclusivo da versão on-line) é um espaço dedicado exclusivamente para artigos inéditos (empíricos, de revisão ou teóricos) que apresentem profundidade teórico-metodológica, gerem conhecimentos novos para a área e contribuições para o avanço da pesquisa em Ensino de Química. 
A sala de aula é essencialmente multimodal, pois nela o professor utiliza um conjunto de modos para construir os significados: a fala, os gestos, a proxêmica, o olhar etc. Geralmente, os professores de ciências naturais usam outro modo semiótico específico com esses modos tradicionais. Esse outro modo influencia a maneira de gesticular e de articular o discurso e pode ser, por exemplo, o desenho no quadro, os modelos bola-vareta, a projeção na tela etc.

De acordo com Nathan e Alibali (2011), gestos podem ser particularmente importantes na sala de aula, pois a compreensão dos estudantes é frequentemente desafiada por um discurso que apresenta novos conceitos e que usa termos que não lhes são familiares. Em tais circunstâncias, os gestos podem desempenhar um papel importante na compreensão dos estudantes. Segundo Goldin-Meadow (2003), para os professores, os gestos representam uma ferramenta de comunicação que, embora usada inconscientemente, auxilia no entendimento do conteúdo que tenha propriedades motoras ou espaciais, particularmente nas ciências da natureza.

No entanto, a multimodalidade não tem tido ainda a ênfase necessária nas pesquisas em educação em ciências. Isso tem sugerido a necessidade de dispensarmos maior atenção ao papel desempenhado por diferentes modos semióticos, e não somente pela linguagem verbal, na construção discursiva do conhecimento científico em sala de aula (Jewitt, 2009).

Piccinini e Martins (2004), em estudo realizado com estudantes da educação básica em aulas de física, afirmam que o uso de diferentes modos semióticos permitiu um fluxo homogêneo de comunicação e auxiliou os estudantes na elaboração conceitual. Padilha e Carvalho (2011), ao analisarem aulas da educação básica, perceberam que a falta das palavras adequadas nas explicações dos conceitos físicos não impediu a comunicação entre os estudantes, uma vez que eles integraram gestos às suas explicações.

Já no ensino superior, em geral, os professores realizam aulas expositivas em que predominam o uso da fala e do gesto. No entanto, nas áreas de ciências naturais, das tecnologias e da matemática, eles usam, além da fala e dos gestos, recursos diversos como projeção na tela, desenhos no quadro, modelos etc. para dar sentido aos conteúdos que trabalham. Esses recursos influenciam a forma como os professores gesticulam e articulam a fala ao gesto.

Os professores são responsáveis pelo agenciamento dos modos que serão utilizados na construção de significados. Acreditamos que essa escolha é determinada pelo potencial comunicativo de cada modo (Kress et al., 2001) e também é influenciada pela experiência do professor.

Acreditamos que uma análise específica, envolvendo os conteúdos ensinados e a multimodalidade, pode trazer contribuições significativas para o processo de ensino-aprendizagem. A partir dessas análises, pretendemos evidenciar algumas formas de articulação entre os modos que podem ocorrer em determinados conteúdos. Neste trabalho, analisamos o uso dos gestos recorrentes (GR) em conjunto com outros modos semióticos durante o compartilhamento de significados em aulas de química orgânica do ensino superior. Estudaremos os GR a fim de entender o uso deles no contexto da química orgânica, a importância dessa recorrência para o compartilhamento e a construção de significados em conjunto com outros modos e o seu efeito anafórico.

Nesse sentido, procuramos responder às seguintes questões de pesquisa: Como ocorre a recorrência dos gestos e em que conteúdos os gestos recorrentes predominam? Como os diferentes modos se articulam na construção de significados relevantes para a química orgânica?

Ao responder a essas questões de pesquisa, procuramos destacar a importância de um tratamento multimodal, e não apenas da linguagem verbal, para a construção de significados em aulas de ciências naturais.

\section{Referencial Teórico}

\section{Multimodalidade e o ensino de ciências}

A multimodalidade é um campo de pesquisa que parte do pressuposto que os significados são produzidos, distribuídos, recebidos, interpretados e refeitos a partir da leitura de vários modos de representação e comunicação e não apenas por meio da linguagem falada ou escrita. Dessa forma, para compreender a comunicação, é necessário ir além da interpretação da linguagem e de seus significados, pois o que demanda compreensão é um conjunto de modos de representação e comunicação (Jewitt, 2009).

Entendemos modo como a representação de meios organizados, regulares e socialmente específicos (Kress et al., 2001) que atuam conjuntamente na construção de significado. Dessa forma, em sala de aula, podemos classificar como modos: o quadro de giz, a tela de projeção, o modelo bola-vareta, a proxêmica, a fala, o gesto, entre outros.

\section{Uso de gestos}

Em um processo comunicativo, as pessoas, no mínimo, fazem uso de gestos e da fala. Para McNeill (2012), o gesto é uma ação manifestamente expressiva que representa imagens sendo geradas como parte do processo da fala. Além disso, para McNeill (2012) e Kendon (2004), os gestos são componentes integrais da fala, ou seja, não são meros substitutos ou acompanhamentos.

A microanálise da comunicação, conduzida numa interação face a face, mostra que a ação corporal visível, incluindo gestos, pode ter papel crucial no processo de interação e comunicação. Gesto é uma forma de expressão que os humanos dispõem e que pode ser usada para uma série de propósitos expressivos diferentes. A maneira como os gestos são criados e utilizados depende das circunstâncias de uso, do propósito comunicativo 
específico da pessoa e de quais outros modos de expressão estão disponíveis (Kendon, 2004).

Para Kendon (2004), o uso dos gestos pode permitir ao interlocutor apreender o enunciado de forma mais vívida e evocativa. Esse autor mostra que o falante usa os gestos para fazer referências dêiticas, para representar objetos ou ações e para pontuar, marcar ou mostrar aspectos da estrutura da fala.

\section{A classificação dos gestos segundo Kendon}

A tipologia gestual adotada neste trabalho será a descrita por Kendon (2004), que é baseada na função dos gestos no processo comunicativo. Em sala de aula, o professor compartilha e constrói significados com os estudantes, sendo assim, identificar as funções do gesto possibilita a identificação da intencionalidade do docente na construção do significado. Assim, quando identificamos que o gesto tem uma função de representar uma ação, por exemplo, quando ela está ensinando o movimento de elétrons entre estruturas químicas, conseguimos evidenciar que o foco do professor, naquele momento, está na ação em si e não no referente estático que ele está usando. Essa classificação faz distinção entre gestos referenciais e gestos pragmáticos. Apresentamos abaixo o fluxograma (Figura 1) com essa tipologia para sua visualização completa.

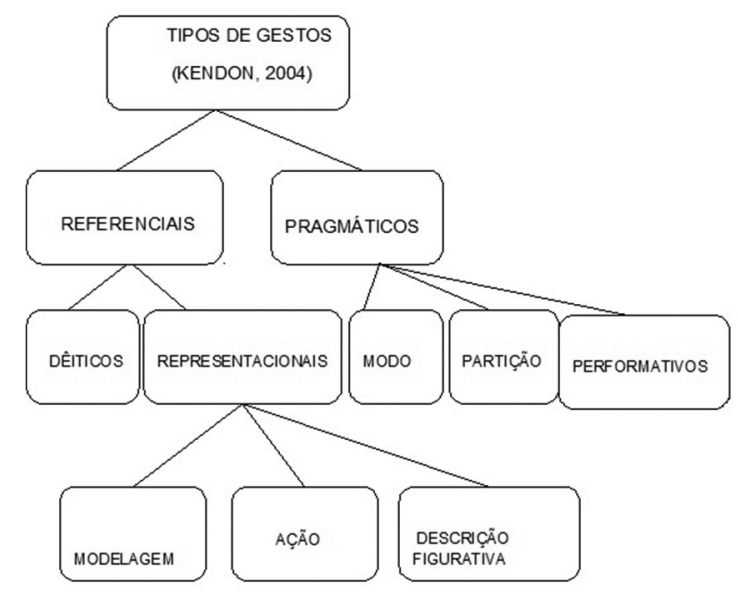

Figura 1. Fluxograma com a tipologia gestual descrita por Kendon (2004).

Gestos referenciais (GR) fazem parte do conteúdo referencial do respectivo enunciado. Estes, por sua vez, são subdivididos em:

a) Gestos representacionais, que se referem a um aspecto do conteúdo do enunciado e são subclassificados em: gestos de modelagem, quando uma parte do corpo é usada para modelar algum objeto. Por exemplo, quando uma professora usa as duas mãos em posição neutra com palmas viradas uma para outra com dedos encurvados formando uma esfera. Ela modela o tamanho do átomo e faz variações nessas esferas para poder comparar diferentes tamanhos de átomos; gestos de descrição figurativa, quando o falante esculpe e/ ou esboça a forma do objeto descrito, ou seja, cria o objeto no ar como, por exemplo, quando uma professora desenha, no espaço compartilhado com os estudantes, um gráfico de energia de ativação; gestos de ação, quando as partes do corpo que estão gesticulando apresentam um padrão de ação semelhante àquele sobre o qual se fala como, por exemplo, no momento em que um professor, estando com a mão aberta, fecha os dedos de uma das mãos para demonstrar a atração dos elétrons por um átomo mais eletronegativo.

b) Gestos dêiticos (ou de apontar), quando o falante aponta o objeto (concreto, virtual ou abstrato) de referência no enunciado.

Os gestos pragmáticos, por sua vez, relacionam-se a aspectos do significado de um enunciado que não fazem parte nem do significado referencial nem do conteúdo proposicional. Os gestos pragmáticos são subdivididos em: (a) gestos de modo, quando o falante dá ênfase ao que está sendo dito no enunciado. Nestes, normalmente, o movimento das mãos geralmente é alternado, batendo a mão para cima e para baixo como um movimento de baqueta; (b) gestos performativos mostram a ação que o falante assume no turno da fala. Eles indicam um pedido, uma súplica, uma oferta, um convite, uma recusa e assim por diante. Por exemplo, quando o falante oferece o que está enunciando esticando a mão supinada em direção ao interlocutor; e (c) gestos de partição, quando pontuam a fala e mostram seus diferentes componentes lógicos.

Kendon (2004) distinguiu, ainda, seis tipos de contribuições que os gestos podem ter para o significado referencial:

a) Gestos emblemáticos, usados em paralelo com palavras ou frases verbais equivalentes, são aqueles que expressam sinais convencionalizados dentro de uma cultura. Em tais casos, embora pareça uma completa redundância a relação semântica entre fala e gesto, o falante pode produzir vários efeitos ao usá-los. Exemplo: ao pronunciar a palavra dois, o falante levanta uma das mãos com os dedos indicador e médio estendidos (também indicando dois) e os mantém nessa posição. Assim, por meio do gesto, o falante enfatiza e prolonga a ideia de dois.

b) Gestos emblemáticos, usados em paralelo com palavras ou frases verbais com significado diferente do gesto, não apresentam redundância semântica entre fala e gesto, porém pode haver uma contribuição significativa para o conteúdo da fala. Exemplo: o falante pronuncia "meu pai cozinhava" e faz um gesto segurando a ponta da orelha com os dedos polegar e indicador. Embora o falante não tenha expressado verbalmente, pode-se entender que seu pai fazia pratos deliciosos.

c) Gestos como especificadores semânticos acrescentam algo ao significado da fala e representam uma forma de ação específica que adiciona informação referencial, tornando o significado do enunciado mais específico. O verbo jogar, por exemplo, pode ser mais bem especificado quando acompanhado de um gesto com movimento que simule o padrão 
de ação realizado pela pessoa engajada no ato de jogar. Assim, se o falante pronuncia jogar e realiza um movimento como se estivesse espalhando um material farináceo sobre uma superfície, a ação refere-se a uma das classes do ato de jogar. Dessa forma, a ação do gesto torna o verbo jogar mais específico.

d) Gestos usados para criar um objeto são usados quando o falante emprega as mãos para criar o objeto ao qual se refere, por meio de modelagem, no espaço compartilhado com o ouvinte. O objeto é criado e apresentado de tal forma que pode ser visto e inspecionado pelos interlocutores. Dessa forma, se o falante estiver fazendo referência a tortinhas de limão (Kendon, 2004, p. 190-191), por exemplo, ele pode usar as mãos para criar as tortinhas e exibi-las para que elas sejam examinadas no espaço compartilhado com o ouvinte.

e) Gestos usados para apresentar a forma, o tamanho, as características ou as relações espaciais do objeto ao qual se refere são também uma forma de exibir padrões de ação que provêm imagens motoras ou visuais dos processos. Um exemplo disso é relatado por Kendon (2004, p. 167-168) quando o falante pronuncia "costumava haver dois queijos em cada caixa", ele estende ambos os braços para frente, na altura da cintura, posiciona as mãos abertas com a palma voltada para baixo e os dedos semiflexionados e as move para baixo repetidas vezes. Esse movimento repetido mostra o posicionamento relativo dos queijos dentro das caixas. Em alguns casos, ao apresentar a forma de um objeto, o falante também cria esse objeto. Portanto, a função dos gestos, apresentada em (d) e (e), pode se sobrepor.

f) Gestos podem ser empregados para criar objetos de referência de expressões dêiticas. Assim, o falante usa gestos que criam o objeto que está sendo referenciado no componente verbal acompanhado de uma palavra dêitica. Como exemplo, Kendon (2004, p.165-166) descreve as caixas nas quais eram recebidos os queijos que seriam posteriormente maturados e vendidos. Ao pronunciar "caixas compridas assim", o falante posiciona as mãos diante dele, com as palmas viradas de frente uma para a outra e as mantém a certa distância uma da outra. A ação das mãos junto com a palavra "assim" mostra o comprimento das caixas.

\section{Gestos recorrentes ou catchments}

Além da tipologia de Kendon (2004), também trabalhamos com os catchments que, segundo McNeill et al. (2001) e McNeill (2005), são gestos que apresentam recorrência ao longo do enunciado. A recorrência pode ser sinalizada pela forma que a mão assume, pela sua localização, orientação do movimento e pelo ritmo, entre outros. Dessa forma, tratamos esses gestos como GR e explicitamos sua recorrência no contexto da sala aula.

Quando McNeill (1992) iniciou a estudar essa categoria de gestos, ele os denominava de gestos coesivos. Para ele, estes funcionavam como elementos linguísticos anafóricos. Posteriormente, essa categoria foi substituída pelo conceito de catchments. Para McNeill (2005), a lógica é que "a recorrência das imagens sugere um tema comum do discurso e o tema do discurso produz gestos com características recorrentes". Sendo assim, as características recorrentes mostram ligações coesivas com a fala que co-ocorrem com o gesto. Dessa forma, ele relata que os GR (catchments) são um tipo de linha imaginária que é executada no discurso para revelar unidades discursivas maiores. Portanto, a identificação desses gestos usados por um falante nos permite determinar como é que este considera e agrupa significados similares em GR relacionados. Da mesma forma, podem-se observar quais significados são colocados e agrupados em outros GR que estão sendo entendidos pelo falante como significados distintos ou menos relacionados.

Nathan e Alibali (2011) relatam que os professores usam estratégias para estabelecer intersubjetividade como, entre elas, os gestos. Eles observaram que estes estabelecem intersubjetividade de duas maneiras: (1) gestos de ligação - grupos de gestos que guiam a atenção (principalmente dêiticos), ou seja, que delineiam correspondências referenciais entre uma representação familiar (ex.: a fórmula plana) e uma nova representação (ex.: a fórmula tridimensional); (2) catchments - são gestos utilizados para retomar ideia já trabalhada.

Neste trabalho, focaremos o uso de gestos em sala de aula do ensino superior e suas interações com outros modos semióticos, ou seja, a multimodalidade em aulas de química orgânica. Para isso, teremos como suporte a semiótica social (Kress, 2001; Jewitt, 2006). Entendemos então a sala de aula como um contexto social em que a aprendizagem é desenvolvida.

O que distingue a semiótica social da tradicional é que a primeira tem seu foco no recurso semiótico, enquanto a segunda tem seu foco no signo, que é arbitrário. Além disso, somente a semiótica social considera o sujeito e sua intencionalidade na construção do significado (Jewitt, 2006). Nessa construção, o sujeito seleciona os recursos semióticos disponíveis tendo em vista aquilo que ele quer comunicar. Dessa forma, entendemos o professor como esse sujeito intencional que faz a escolha dos recursos para construir significados em sala de aula.

Segundo Laburu e Silva (2011), a semiótica oferece novas e diferentes perspectivas para uma nova e fértil área de investigação e que podem ser traduzíveis em procedimentos concretos para um melhor alinhamento entre ensino e aprendizagem de tal forma que o primeiro esteja a serviço do segundo, fornecendo orientações pedagógicas para a prática cotidiana de sala de aula.

\section{Metodologia}

Para identificar os GR, analisamos a filmagem das aulas de uma professora de química orgânica do ensino superior. As aulas foram filmadas durante um semestre letivo, pois consideramos que, para configurar a recorrência de um gesto, 
é necessária a análise de uma sequência de aulas para uma possível visualização da retomada da ideia. Essas aulas faziam parte do planejamento da professora e não houve nenhuma interferência na forma como ela as conduzia.

A professora selecionada tem mais de 10 anos de experiência e reconhece as dificuldades de aprendizagem dos estudantes. Isso faz com que esta utilize diversos modos semióticos na construção de significados. Ela não tinha conhecimento sobre os objetivos da pesquisa.

Assistimos a todas as aulas na íntegra e buscamos encontrar gestos realizados pela professora de forma recorrente e que apresentam orientação espacial semelhante (McNeill, 2005). Esses gestos semelhantes eram utilizados para retomada de uma ideia principal.

Após a identificação dos gestos, associamos quais foram os modos semióticos (Kress, 2001) que aparecem em conjunto com eles no momento da sua realização. Além disso, classificamos esses gestos seguindo a tipologia gestual descrita por Kendon (2004), pois ela é baseada na função do gesto e assim conseguimos perceber qual foi a função predominante em cada um dos GR. Apresentamos as transcrições da linguagem verbal de alguns momentos em que estes foram realizados e escrevemos em caixa alta as palavras que coincidem com o golpe do gesto. Ele é caracterizado pelo ápice do movimento. As figuras neste trabalho, em que aparece a professora realizando os gestos, mostram o momento do golpe. Em algumas vezes, o golpe está associado a apenas uma palavra e, em outras, está associado a mais de uma palavra. Essa diferença ocorre devido à velocidade de fala da professora.

\section{Resultados}

Durante o semestre, identificamos 23 GR diferentes. No Gráfico 1, podemos observar que quatro destes ocorreram por mais de 100 vezes durante o semestre. Sendo assim, neste trabalho, faremos a análise desses quatro.

Alguns desses gestos se concentram em conteúdos específicos, enquanto outros ocorrem em vários temas durante o semestre. Para estes que ocorrem em diversos temas, a função de coesão tornou-se ainda mais evidente.

Em momentos distintos das aulas, a professora realizou esses GR em conjunto com diversos modos. O modo semiótico utilizado por esta pode ter uma grande influência sobre a forma como ela gesticula, pois o modo determinará o que e como se fala (Moro et al. 2011). É nesse sentido que observamos que ela faz diferentes escolhas dos modos que utilizará em conteúdos distintos.

Visando à coerência com os dados apresentados no Gráfico 1, trabalharemos usando a mesma numeração dos gestos que ocorreram mais vezes. Portanto, faremos a análise do GR 2, GR 3, GR 5 e GR 16.

\section{1) Gesto que indica atração de elétrons}

O GR 2 foi realizado pela professora para indicar a atração de elétrons e ocorreu 132 vezes durante o semestre. Nos momentos em que o realizava, ela pronunciava termos como: "mais eletronegativo"; "atrair mais elétrons"; "tá precisando receber elétrons"; "espécie rica em elétrons".

Para realizar o gesto, ela posicionava o braço pronado ou

\section{Gestos recorrentes identificados}

\section{n número de vezes em que o gesto ocorreu}

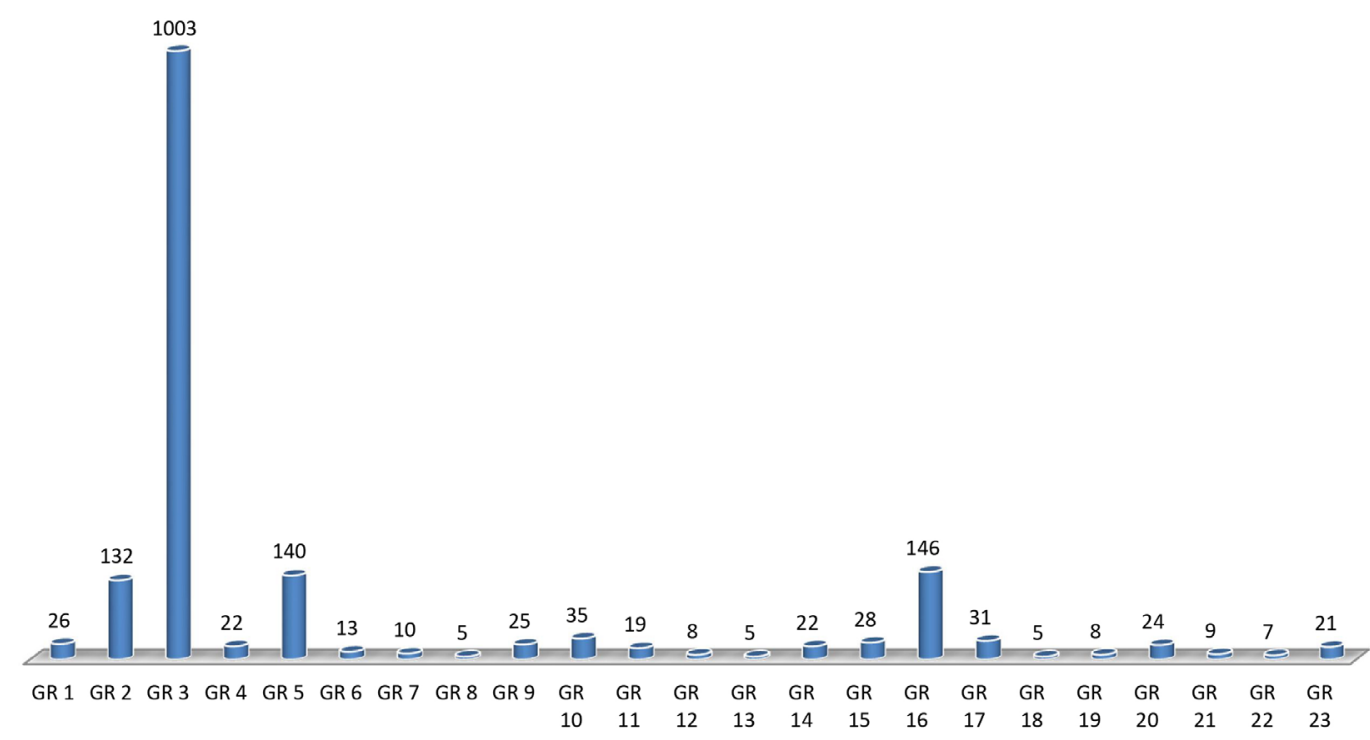

Gráfico 1. Número de vezes em que cada gesto recorrente ocorreu durante o semestre. 


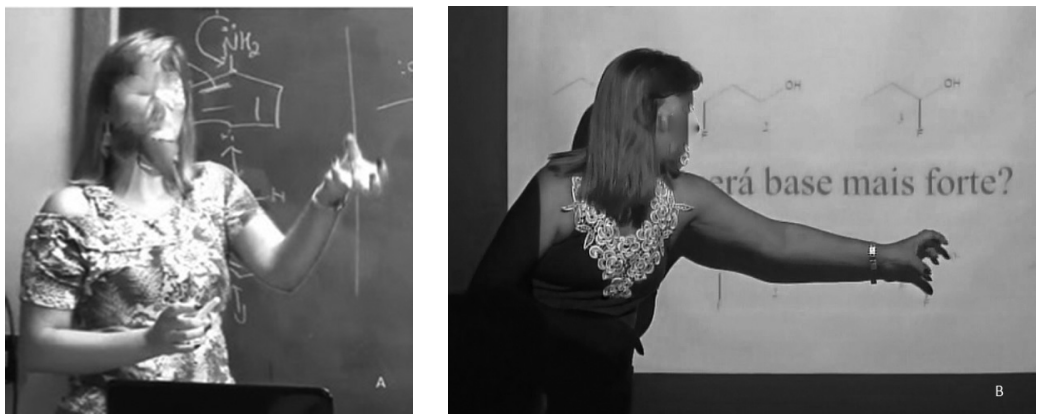

Figura 2. GR 2 sendo realizado em conjunto apenas com a fala (A) e em conjunto com a fala e a tela de projeção (B).

supinado e, com as mãos, fazia um movimento em que juntava os cinco dedos no centro, fechando-os em forma de cacho. $\mathrm{Na}$ Figura 2, temos a imagem com o GR 2 sendo realizado em conjunto com a fala (Figura 2A) e com a tela de projeção (Figura 2B).

Em aulas em que o assunto trabalhado era ressonância, a professora fez esse gesto acompanhado de frases como: "quanto mais eletronegativo for um átomo, maior TENDÊNCIA DE?/ atrair os elétrons"; "o oxigênio é mais eletronegativo, não é? então ele VAI ATRAIR o par de elétrons"; "se o cloro é MAIS ELETRONEGATIVO, ELE ATRAI o par de elétrons"; "se existir alguma estrutura de ressonância, vai ser aquela onde o átomo mais eletronegativo está ATRAINDO o par de elétrons". Em alguns desses momentos, ela fazia referência às estruturas de ressonância desenhadas no quadro. Sendo assim, observamos no Gráfico 2 que, em $8 \%$ das vezes, a professora utilizou o conjunto fala, gesto e quadro.

\section{Modos semióticos - gesto 2}

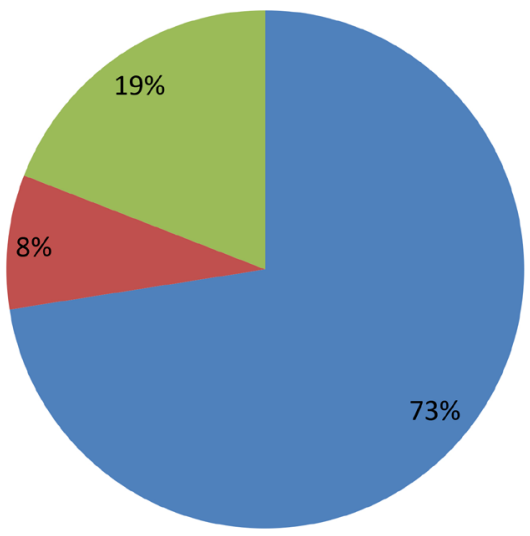

fala e gesto

fala,gesto e quadro

fala , gesto e tela de projeção

Gráfico 2. Os modos semióticos utilizados junto com o GR 2.

Esse gesto foi realizado pela primeira vez em aulas que envolviam essa temática e ocorreu por 27 vezes nessas aulas. Apesar de o gesto surgir nesse assunto, ele não predominou. Esse fato pode ser justificado, pois acreditamos que, no tema de ressonância, esse não é o conceito essencial para o entendimento do assunto e sim um conceito auxiliar. O estudante precisa identificar essencialmente qual é o movimento dos elétrons e, para isso, qual espécie atrai mais ou menos os elétrons. No entanto, o essencial para gerar novas estruturas de ressonância é entender qual é esse movimento dos elétrons, para onde eles vão e como criam a nova estrutura.

Quando a temática foi reações químicas, as frases que acompanharam o gesto foram: "se o flúor é mais eletronegativo, ele SEGURA BEM esse par de elétrons"; "então o oxigênio é mais eletronegativo por efeito indutivo, ELE VAI ATRAIR mais também"; "os átomos de cloro vão PUXAR o par de elétrons para ele". Nesses momentos, observamos que ele ocorreu junto com fala e tela projeção, representando $19 \%$ das vezes (vide Gráfico 2). O uso desse conjunto deve-se ao fato de que a professora fazia explicações de reações entre ácidos e bases, e essas substâncias estavam representadas na tela de projeção. Nesse sentido, ela precisava gesticular ancorada nesse outro modo para tornar mais evidente o referente.

Na temática de reações químicas, esse gesto ocorreu por 106 vezes do total das 132. Além disso, ressaltamos que em 92 vezes ele ocorreu no tema reações entre ácidos e bases. Quando se pensa nesse tipo específico de reação, é preciso que o estudante compreenda quais são os compostos e/ou grupos que têm mais tendência a atrair elétrons e aqueles que têm menor tendência. $\mathrm{O}$ ataque dos grupos ocorrerá em função desse caráter que foi definido para uma substância frente a outra. Dessa forma, a professora dá ênfase ao assunto que é essencial para esse tópico usando esse GR e, portanto, ele aparece concentrado nessa temática.

Em aulas posteriores, que tratam de reações químicas de outros tipos, a professora realiza o gesto por um número de vezes bem menor (14 vezes). Nessas outras reações, o enfoque não era o entendimento da atração dos elétrons e, portanto, a professora usa o GR apenas para retomar a ideia essencial que foi estabelecida.

Além desses conjuntos de modos, percebemos também no Gráfico 2 que houve predominância do conjunto fala e gesto $(73 \%)$. Entendemos que essa predominância ocorre devido ao fato de a professora realizar esse gesto, na maioria das vezes, usando um referente abstrato que se encontra apenas na fala. Além disso, o corpo dela está voltado para os estudantes, sendo, dessa forma, independente em relação aos modos quadro e tela de projeção.

Como esse gesto foi utilizado para representar grupos atraindo elétrons, podemos caracterizá-lo como um gesto 

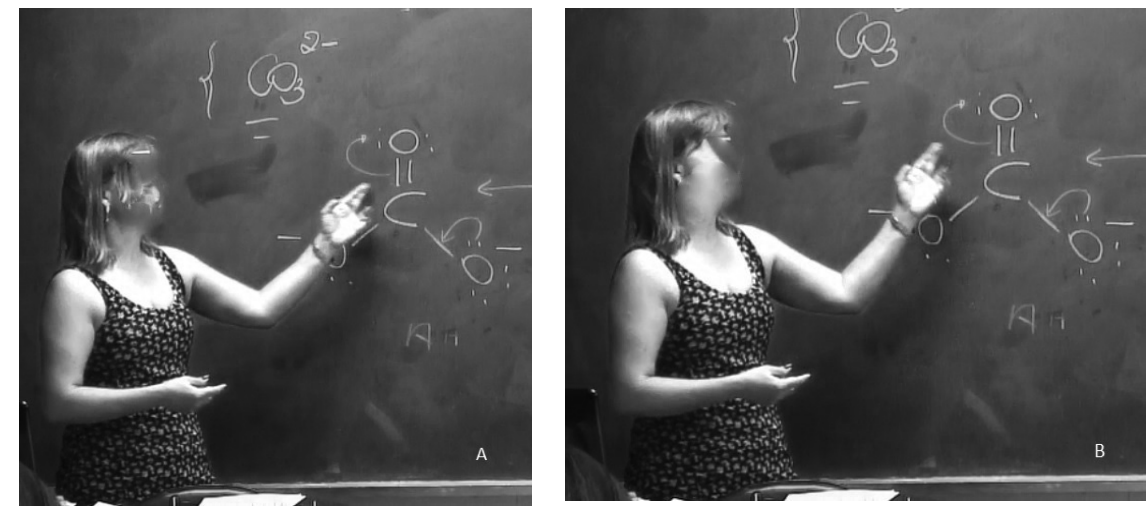

Figura 3. GR 3 sendo realizado em conjunto com a fala e o quadro ( $A$ e $B$ ).

referencial representacional de ação segundo a tipologia de Kendon (2004).

\section{2) Gesto que representa o movimento de elétrons}

O GR 3 foi realizado pela professora para representar o movimento de elétrons e ocorreu 1003 vezes durante o semestre. Estes foram realizados pela professora com o braço pronado ou supinado e as mãos em diferentes posições descrevendo um movimento curvo, ou seja, a seta curva que representa o movimento de elétrons na química. Na Figura 3, podemos observar o gesto sendo realizado em conjunto com a fala e o quadro.

$\mathrm{Na}$ temática de ressonância, esse gesto foi utilizado pela professora para representar o movimento de elétrons entre as estruturas de ressonância, fazendo modificações entre ligações covalentes simples e duplas e gerando diferentes regiões ricas em elétrons. Nesses momentos, a professora utilizou falas como: "então o par de elétrons TRANSFORMA-SE em dupla/e dupla TRANSFORMA-SE em par de elétrons/e isso é estrutura de ressonância".

Nessa temática, o gesto ocorreu 276 vezes, ou seja, com uma porcentagem significativa sobre o total. Para explicar para os estudantes como gerar as estruturas, a professora indicava qual deveria ser o movimento dos elétrons. Ao realizar o gesto por várias vezes, ela cria um enfoque nesse movimento dos elétrons.

Quando a temática passou a ser reações químicas, a professora demonstrava com o gesto qual seria o movimento dos elétrons para que ocorresse a quebra de ligações nos reagentes e, assim, evidenciava também qual seria o produto formado. Nesses momentos, ele ocorreu em conjunto com falas como: "então a essência de mecanismo é isso/mostrando PARA ONDE O PAR DE ELÉTRONS ESTÁ INDO e o que está sendo formado lá nos produtos"; "a gente pode mostrar parzinho de elétrons CAPTURANDO o próton"; "tá claro o mecanismo? Como que a gente representa? Pega a setinha do par de elétrons/ ATACA o carbono por trás"; "oxigênio comporta melhor o par de elétrons/então é claro que essa LIGAÇÃO AQUI É QUE VAI SER ROMPIDA, melhor grupo abandonador/então ATACOU esse carbono/QUEBRA essa ligação"; "então a água vem/e VAI ATACAR ESSE carbono aqui/que é o mais substituído"; "a dupla ligação ATACA o reagente de modo a formar o carbocátion mais estável".

Ao analisarmos a temática reações químicas, observamos esse gesto recorrente ocorrendo 727 vezes. Para a compreensão das reações químicas, é preciso que o estudante entenda quais as ligações químicas estão sendo rompidas e formadas. Quando se trata desse entendimento em química orgânica no ensino superior, é necessário que o estudante entenda o mecanismo proposto para o processo, ou seja, qual será o movimento dos elétrons que geram as quebras e as formações das ligações. Portanto, a professora enfatiza nessa temática o movimento de elétrons que transforma os reagentes em produto, visando entender o mecanismo da reação. No Gráfico 3, podemos observar uma distribuição mais uniforme do conjunto de modos utilizados.

\section{Modos semióticos - gesto 3}

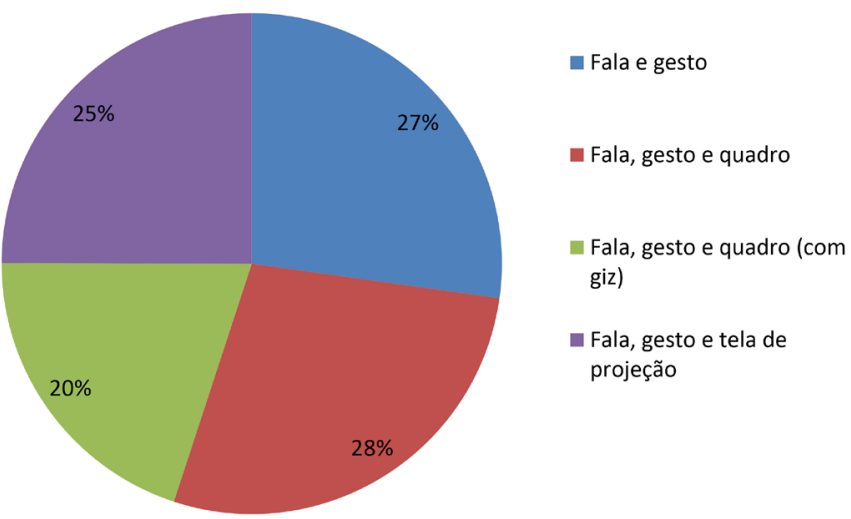

Gráfico 3. Os modos semióticos utilizados junto com o GR 3.

Podemos perceber que a realização desse gesto junto ao quadro ocorreu em $48 \%$ das vezes, somando as regiões quadro e quadro com giz. Esse fato pode ser justificado devido à professora desenhar no quadro os mecanismos de reações que ela propõe para os estudantes e, então, fazer as explicações com esses desenhos. Já o gesto em conjunto com a tela de projeção ocorreu quando ela mostrava um exemplo de reação na tela ou quando mostrava diferentes estruturas de ressonância. 
No total, o gesto ocorre com outro modo, seja ele o quadro ou a tela de projeção, em $75 \%$ dos casos. Isso indica que esse gesto, além de poder ser caracterizado como um gesto referencial representacional de ação, segundo a tipologia de Kendon (2004), também funciona como um gesto dêitico, pois faz referência a objetos desenhados no quadro ou na tela de projeção. Ele foi classificado como referencial representacional de ação porque representa a ação de movimentar-se que os elétrons estão realizando na molécula em questão. No entanto, ele também tem função dêitica justamente porque a professora faz referência direta a objetos moleculares desenhados no quadro ou representados na tela de projeção e, ainda, indica a direção do movimento desses elétrons. Dessa forma, considerando Kendon (2004, p. 202), podemos classificar esse gesto com um gesto combinado de ação e dêitico. Isso também reforça a observação de McNeill (2005, p. 41) de que os gestos apresentam principalmente uma dimensionalidade, ou seja, não se pode falar que um gesto seja $100 \%$ dêitico ou $100 \%$ referencial. Portanto, para ele, o gesto terá uma mistura de funções.

O grande número de vezes em que esse gesto é realizado evidencia que ele está relacionado a um conceito essencial para toda a química orgânica trabalhada naquela semestre. Com essa recorrência, a professora retoma o conceito essencial sem a necessidade de fazer a explicação completa do assunto como faz nas primeiras vezes em que o conceito e o gesto surgem.

Devemos lembrar, portanto, que além desse gesto se distribuir em várias temáticas durante o semestre, ele foi realizado em conjunto com diversos modos. Entendemos então que, para diferentes assuntos, a professora faz escolha de diferentes modos para conseguir construir o significado com os estudantes.

\section{3) Gesto que indica ligação química}

A professora realizou o GR 5 para indicar ligação química e par de elétrons. Na temática de ressonância, ela mostrava as ligações que estavam mudando de lugar para criar novas estruturas de ressonância. Nos capítulos de reação química, o gesto foi usado para mostrar qual ligação seria rompida ou formada.

No momento em que realizava esses gestos, a professora estava com o braço e a mão pronados e mantinha dois dedos estendidos distantes um do outro e os outros dedos flexionados.
Sendo assim, geralmente, ela usava os dedos estendidos para apontar a ligação química e os átomos ligantes e, portanto, podemos classificar o GR 5 como um gesto dêitico (Kendon, 2004). Na Figura 4, temos esse gesto sendo realizado em conjunto com a fala, o quadro e a tela de projeção.

É importante ressaltar que ele é dêitico não só pelo fato de a professora estar apontando algo, mas também pelo fato de indicar, algumas vezes, o número dois, que no caso representa dois elétrons.

Na temática de ressonância, nos momentos em que realizou o gesto, ela pronunciou frases como: "então/ressonância só pode ter quando/eu tiver uma DUPLA/conjugada com algum sistema"; "então eu tenho DUPLA/SIMPLES/par de elétrons não ligantes/eu posso ter ressonância aqui/mas eu tenho DUPLA/SIMPLES/DUPLA aqui também/então eu posso ter ressonância aqui também".

Nessa temática, o gesto ocorreu 91 vezes. Para analisar a diferença entre as estruturas de ressonância, é essencial que o estudante identifique as diferentes ligações químicas nas estruturas. Para isso, a professora indica com o gesto a ligação química que mudou de lugar para gerar as novas estruturas. Dessa forma, essa identificação se tornou recorrente ao longo desse assunto.

Já quando a temática era reações químicas, ela o realizou com expressões como: "então/a capacidade que esse cloro tem/de acomodar o par de elétrons/deixado pela quebra da LIGAÇÃO H-Cl/vai definir se isso daqui é um ácido forte/ ou um ácido fraco"; "quanto maior for o comprimento da ligação/do halogênio ao átomo de carbono/mais fraca será a LIGAÇÃO".

Nessa temática, que ocorre em um número maior de aulas, o gesto aconteceu 46 vezes. Se considerarmos esse número de vezes, percebemos que a identificação das ligações químicas em uma reação é um fator importante, mas não é o essencial. Sendo assim, entendemos que a professora fez a identificação das ligações para facilitar a visualização do estudante de onde partiria o movimento dos elétrons e aonde eles chegariam.

No Gráfico 4, observamos que esse gesto ocorreu $51 \%$ das vezes junto ao quadro. Isso pode ser justificado pelo fato de, na maioria das vezes, a professora indicar ligações químicas que estavam desenhadas no quadro.
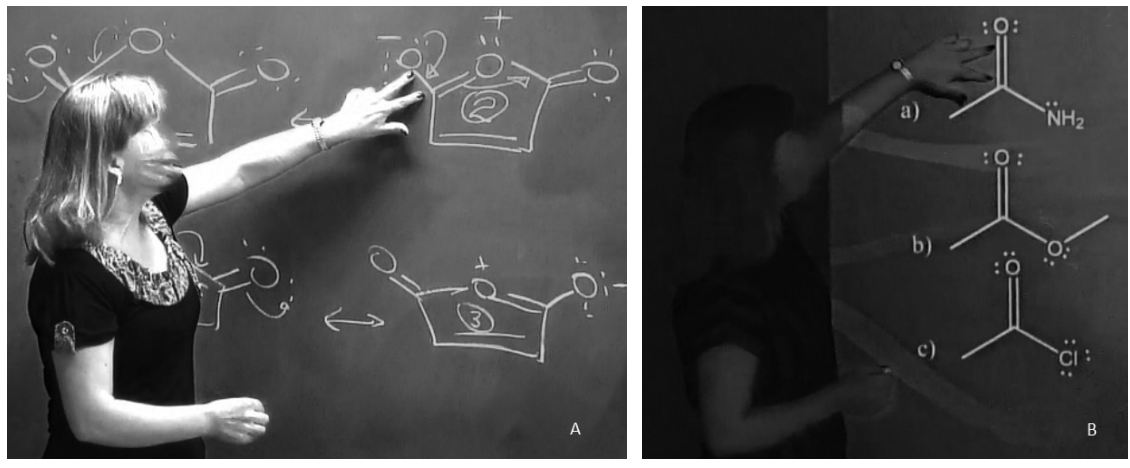

Figura 4. GR 4 sendo realizado em conjunto com a fala e o quadro (A) e em conjunto com a fala e a tela de projeção (B). 
Modos semióticos - gesto 3

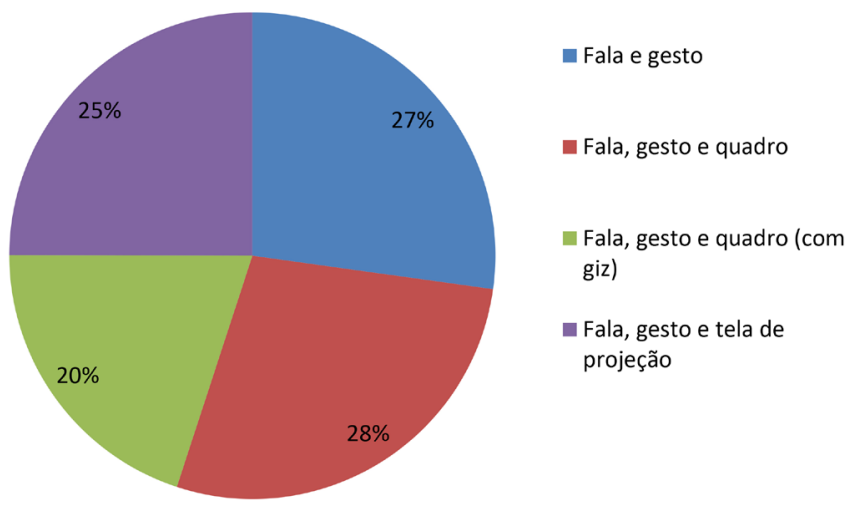

Gráfico 4. Os modos semióticos utilizados junto com o GR 5.

Nesse gesto, podemos perceber com clareza como o outro modo semiótico influencia na gesticulação. Ele teve um caráter dêitico, tendo em vista que a professora o realizou para apontar as ligações químicas às quais ela se referia na fala e estavam representadas no outro modo.

Além disso, apesar de ele aparecer em diversos temas, sempre foi usado para um mesmo significado e acompanhado na fala pelas palavras: ligação, simples, dupla, par de elétrons. Todos esses termos se referem à existência do par de elétrons, e a professora evidencia isso em falas como: "lembrando que ligação é par de elétrons".

\section{4) Gesto que representa o giro horário ou anti-horário}

O GR 16 foi realizado pela professora para descobrir a configuração R ou S de estereocentros de moléculas. Para definir essa configuração, ela precisa descobrir se o giro dos ligantes, do de maior prioridade para o de menor prioridade, ocorria no sentido horário ou anti-horário.

Com esse GR, a professora representava o giro dos ligantes. Dessa forma, ela segurava o modelo bola-vareta com uma das mãos e com a outra mão fazia um giro, considerando a classificação da prioridade dos ligantes que era feita anteriormente. Na Figura 5, podemos observar o gesto sendo realizado em conjunto com a fala e o modelo bola-vareta.

A professora realizava o gesto em conjunto com falas como: "agora eu vou rodar o que/PRETO PARA O BRANCO/PRETO
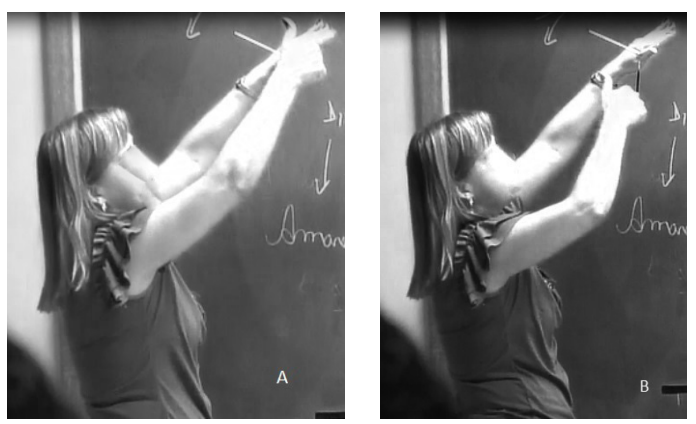

Figura 5. GR 16 sendo realizado em conjunto com a fala e o modelo bola-vareta (A, B e $C)$.
PARA O BRANCO que SENTIDO EU ESTOU TENDO/ SENTIDO HORÁRIO/horário/R". Observe que nessa frase temos quatro gestos sendo realizados, pois a professora segura o modelo e realiza quatro giros enquanto está falando. Nesse caso, ela identificou os grupos por cores diferentes e, portanto, chama-os de preto e branco, indicando as cores que estavam no modelo bola-vareta. É importante ressaltar que foi comum que esse gesto fosse realizado por várias vezes numa mesma frase, portanto, isso fez com que ele aparecesse com mais de 100 ocorrências.

Em outros momentos, a professora numerava os grupos de acordo com a prioridade e fazia o gesto em conjunto com a fala, utilizando a numeração, por exemplo: "o giro é sempre do de maior prioridade para o de menor/1, 2, 3/1, 2, 3". Ela realizou o gesto nas duas vezes enquanto fazia a contagem de 1 para 3.

Nos momentos em que a professora realizou o GR 16 no quadro, ela mantinha uma das mãos fixa como se estivesse segurando a molécula desenhada no quadro e, com a outra mão, realizava o giro. Um exemplo desses momentos pode ser observado na Figura 6. Dessa forma, a professora faz o gesto no quadro de maneira semelhante ao que realiza com o modelo bola-vareta na mão.

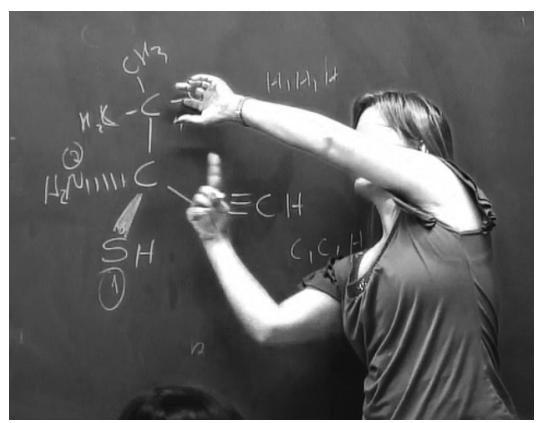

Figura 6. GR 16 sendo realizado em conjunto com a fala e o quadro.

Observando o Gráfico 5, percebemos que o GR 16 foi o que ocorreu em conjunto com maior número de modos. Além

Modos semióticos - gesto 16

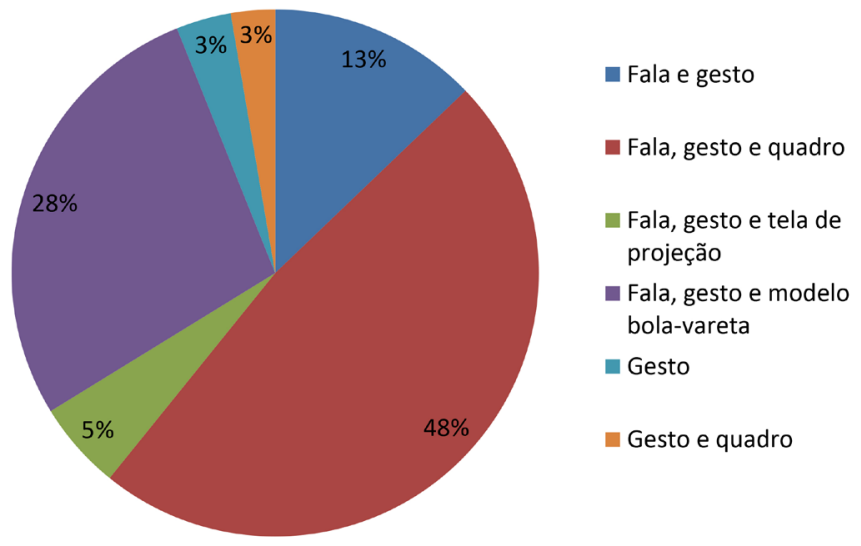

Gráfico 5. Os modos semióticos utilizados junto com o GR 16. 
disso, observamos a predominância do conjunto fala, gesto e quadro, seguida do conjunto fala, gesto e modelo bola-vareta.

O modelo bola-vareta é um suporte para a explicação, sendo essencial para colocar em circulação o saber fazer químico na sala de aula. Considerando De Saint-Georges (2008), o modelo permite que o foco de atenção dos estudantes seja direcionado para um mesmo objeto, orientando-os sobre diferentes aspectos desse objeto de conhecimento.

Nas vezes iniciais em que o gesto ocorreu, ela usou como suporte o modelo bola-vareta e, com o passar das aulas, ela começou a usar o quadro. Acreditamos que essa escolha foi feita levando em consideração o menor nível de abstração da representação desses estereocentros com o modelo bola-vareta, pois com esse modelo, fica mais plausível o entendimento tridimensional da molécula e, consequentemente, a visualização da configuração do estereocentro.

Considerando-se o fato de que com esse gesto a professora demonstrava para os estudantes qual deveria ser o sentido do giro dos ligantes de um estereocentro, podemos classificá-lo como um gesto dêitico segundo Kendon (2004).

Como ele foi realizado pela professora para analisar a configuração $\mathrm{R}$ ou $\mathrm{S}$ do estereocentro de um enantiômero, ele ocorreu 104 vezes em aulas que envolviam esse tema. Nesse caso, a professora retoma com o gesto a ideia do giro entre os ligantes, e a sua maior recorrência nessas aulas evidencia qual deve ser o conceito essencial a ser entendido quando se trata de estereoquímica.

Apesar de esse gesto ocorrer novamente em aulas em que a temática central não era essa, ele foi usado para retomar a ideia, pois em algumas reações químicas, a professora precisou identificar a configuração R ou S dos reagentes e dos produtos. Nesses momentos, ela faz uma retomada do conceito de forma mais rápida, não se preocupando mais em ensiná-lo e sim em retomá-lo como um conceito auxiliar para o entendimento das reações químicas que estavam sendo trabalhadas.

\section{Discussão}

Ao relacionar esses $4 \mathrm{GR}$ com as temáticas em que eles apareceram, podemos responder à nossa pergunta de pesquisa em relação aos conteúdos. Percebemos que eles ocorrem com os conceitos essenciais que se espera que o estudante aprenda na química orgânica estudada nessas aulas.

Acreditamos, portanto, que eles foram realizados por um maior número de vezes durante o semestre, tendo em vista o foco da professora em enfatizar as ideias-chave da disciplina. Além disso, a identificação desses GR mostra que as ideias essenciais foram retomados pela professora por várias vezes durante $\mathrm{o}$ semestre. Com isso, ela promove coesão entre os conteúdos estudados, criando uma relação e, até mesmo, evidenciando uma dependência entre certos temas. Essa coesão é relatada por McNeill (2005), que considera que os GR criam uma linha que corre ao longo do discurso, promovendo coesão. Pereira (2010) observa que a repetição do gesto e da correferencialidade estão ligados a mecanismos de coesão, sendo que o gesto marca a organização textual a partir do espaço e a anáfora marca a organização textual a partir de elementos também textuais.

O termo anáfora vem do grego e significa carregar para trás, definindo toda retomada de um elemento anterior em um texto (Pereira, 2010). Para McNeill (2005), os GR funcionam como elementos linguísticos anafóricos. Nas nossas análises, percebemos que o sentido anafórico pode ser retomado pela unidade fala/gesto/outro modo, fala/gesto ou apenas pelo gesto. Nos casos em que é retomado apenas pelo gesto, acaba-se criando uma linguagem convencionalizada naquele contexto social, tranformando dessa forma o GR num gesto emblemático. Essas características revelam a importância dos GR nesse contexto. É importante lembrar que os gestos emblemáticos fazem sentido para os membros de uma mesma cultura. Por exemplo, o gesto de OK dos norteamericanos tem um sentido para os membros daquela cultura e, para os membros de outra cultura, pode ter um sentido diferente. Essas características revelam a importância dos GR nesse contexto, pois com o tempo, cria-se uma cultura de sala de aula que tem seus próprios gestos que funcionam como emblemas.

Entendemos que, ao concluir a disciplina, o mais importante que o estudante precisa compreender é: identificar as ligações químicas que participam das reações e as que geram diferentes estruturas de ressonância; movimentar os elétrons de maneira a propriciar quebra e formação de ligações e também gerar novas estruturas de ressonância; e manusear o modelo bola-vareta com o intuito de visualizar a representação tridimensional da molécula e, então, identificar as características relacionadas à estereoquímica. Nesse caso, é relevante lembrar o que Jewitt (2006) afirma acerca dos signos como algo motivado e transformativo, ao contrário do que afirma Saussure (1962), de que os signos são sempre arbitrários. Jewitt (2006) enfatiza o contínuo trabalho social envolvido na produção e manutenção de convenções de significados, ou seja, a realização do gesto foi motivada pela presença do outro modo semiótico e o trabalho contínuo que a professora faz, nesse contexto social, permite sua manutenção e convencionalização.

O que motiva a escolha da pessoa por um modo semiótico ou outro na construção de significado em um contexto social é o interesse (Jewitt, 2006). Observamos que a escolha dos modos semioticos utilizados pela professora em conjunto com esses gestos está relacionada com a ênfase que ela quer dar em cada assunto. $\mathrm{O}$ modo escolhido favorece o direcionamento para um determinado aspecto que ela quer trabalhar.

Jewitt (2006) comenta que os professores têm um papel ativo e crucial na construção de significados e em dar forma aos recursos usados para conferir significado. A autora ainda relata que o agenciamento de quem constrói o signo está envolvido no processo de representação. A professora escolhe modos semióticos específicos de acordo com a representação que quer criar. Observamos que o modo mais escolhido foi o 
quadro. Tendo em vista a experiência desta, acreditamos que esse seja o modo mais familiar para ela, o que corrobora a afirmação de Jewitt (2006) que o uso do modo semiótico cria familiaridade. Além disso, essa familiaridade propicia o uso desse modo semiótico com mais propriedade.

\section{Considerações Finais}

A partir da identificação dos GR e de suas relações com os conteúdos trabalhados, conseguimos responder à nossa primeira questão de pesquisa: Como ocorre a recorrência dos gestos e em que conteúdos os gestos recorrentes predominam? A recorrência de gestos ocorre sempre num contexto em que é necessário dar coesão ao discurso. Em relação aos conteúdos, esses gestos predominam em conceitos considerados essenciais ao entendimento do conteúdo de química orgânica trabalhado naquele semestre. Assim, o mais importante que o estudante precisa compreender nesse semestre é identificar as ligações químicas que participam das reações e as que geram diferentes estruturas de ressonância; e movimentar os elétrons de maneira a propriciar quebra e formação de ligações e também gerar novas estruturas de ressonância. Acreditamos que essa repetição gestual realizada pela professora ocorre devido à ênfase que ela quer dar a esses significados.

Observamos também que a recorrência do gesto sinaliza qual é o conceito principal a ser entendido em cada temática ensinada pela professora. Dessa forma, os GR se tornam uma ferramenta para o professor enfatizar alguns conceitos que são fundamentais na disciplina. Ao repetir o que está sendo ensinado, ela auxilia no entendimento da maioria dos estudantes, pois aquele que não havia entendido o que já foi explicado terá a oportunidade de entender no momento da repetição, e aqueles que já haviam entendido têm a oportunidade de ressignificar o conceito que construíram.

Em relação à nossa segunda questão de pesquisa - Como os diferentes modos se articulam na construção de significados relevantes para a química orgânica? -, as aulas analisadas nos permitiram observar que a professora constrói significado por meio da interação entre os modos semióticos. O modo utilizado por ela pode ter uma grande influência sobre a forma como gesticula e sobre qual é o enfoque que dá naquele momento. Kress (2001) faz a pergunta para a qual ele não tem uma resposta pronta: Qual é o melhor modo a ser escolhido pelo professor? A partir dos nossos dados, percebemos que o modo mais adequado é aquele com o qual o professor tem mais familiaridade. Além disso, o modo escolhido é determinado pelo objetivo da professora em dar enfoque a certos aspectos do conteúdo. Sendo assim, compreender o papel desempenhado pelos vários modos permite ao professor fazer escolhas dos modos que julga mais apropriado para serem utilizados no ensino de um determinado conteúdo. Percebemos que até um gesto de apontar, que parece ser simples e rotineiro, tem uma função fundamental em sala de aula para determinar claramente a que professora está se referindo. Nesse sentido, um melhor entendimento da multimodalidade em sala de aula pode contribuir para que a construção de significados seja mais efetiva.

A experiência da professora permite que ela saiba as possíveis dificuldades dos estudantes relacionadas a cada tema. Consequentemente, faz essa escolha de modos tendo como foco essas possíveis dificuldades e a forma que julga mais adequada para tornar mais claro o entendimento de um determinado conceito.

Portanto, esse trabalho indica caminhos para cursos de formação de professores, visando à compreensão do papel dos modos em atos comunicativos que ocorrem na sala de aula e do papel da recorrência de ideias essenciais quando está se construindo um novo conceito. É necessário que, nos cursos de formação, sejam apresentadas essas estratégias, evidenciando a possibilidade do ensino de determinados temas com diversos modos. Além disso, deve-se estimular a reflexão em relação ao uso da multimodalidade no ensino, deixando claro que a escolha dos modos influencia diretamente na aprendizagem.

\section{Referências}

DE SAINT-GEORGES, I. La multimodalité et ses ressources pour l'enseignement - apprentissage. In: FILLIETTAZ, L.; DE SAINTGEORGES, I.; DUC, B. Vos mains sont intelligentes!: interactions en formation professionnelle initiale. Genève: Cahiers de la section des sciences de l'éducation, 2008. p. 117-158.

JEWITT, C. Technology, literacy, learning: a multimodality approach. London: Routledge, 2006.

The routledge handbook of multimodal analysis. London: Routledge, 2009.

GOLDIN-MEADOW, S. Hearing gestures: how our hands help us think. Massachusetts: Belknap, 2003.

KENDON, A. Gesture: visible action as utterance. Cambridge: Cambridge University Press, 2004.

KRESS, G. et al. Multimodal teaching and learning: the rhetorics of the science classroom. London: Continuum, 2001.

LABURÚ, C.E.; SILVA, O.H.M. Multimodos e múltiplas representações: fundamentos e perspectivas semióticas para a aprendizagem de conceitos científicos. Investigações em Ensino de Ciências, v. 16, p. 7-33, 2011.

McNEILL, D. Gesture \& thought. Chicago: University of Chicago Press, 2005.

Hand and mind: what gestures reveal about thought. London: University of Chicago Press, 1992.

How language began: gesture and speech in human evolution. Cambridge: Cambridge University Press, 2012.

McNEILL, D. et al. Catchments, prosody and discourse. Gesture, v. 1, n. 1, p. 9-33, 2001.

MORO, L.; MORTIMER, E.F.; QUADROS, A.L.; COUTINHO, F.A.; SILVA, P.S.; PEREIRA, R.R.; SANTOS, V.C.O. Uso de gestos em aulas de química: a influência de um terceiro modo semiótico. IN: ENCONTRO NACIONAL DEPESQUISA EM EDUCAÇÃO EM CIÊNCIAS, 8, 2011. Anais..., Campinas, 2011. 
NATHAN, M.J.; ALIBALI, M.W. How gesture use enables intersubjectivity in the classroom. In: STAM, G.; ISHINO, M. (Eds.). Intergrating gestures: the interdisciplinary nature of gesture. Amsterdam: John Benjamins, 2011. p. 257-266.

PADILHA, J. N.2011PADILHA, J.N.; CARVALHO, A.M.P. Relações entre os gestos e as palavras utilizadas durante a argumentação dos estudantes em uma aula de conhecimento físico. Revista Brasileira de Pesquisa em Educação em Ciências, v. 11, p. 25-40, 2011.
PEREIRA, A.C.C. Os gestos das mãos e a referenciação: investigação de processos cognitivos na produção oral. 2010. Tese (Doutorado) Universidade Federal de Minas Gerais, Belo Horizonte, 2010.

PICCININI C.; MARTINS I. Comunicação multimodal na sala de aula de ciências: construindo sentidos com palavras e gestos. Ensaio: pesquisa em ensino de ciências. Belo Horizonte, v. 6, n. 1, p. 1-14, 2004.

SAUSSURE, F. Cours de linguistique générale. Paris: Payot, 1962. 